\title{
Seleksi Fitur dengan Information Gain untuk Meningkatkan Deteksi Serangan DDoS Menggunakan Random Forest
}

An Information Gain Feature Selection to Improve DDoS Detection using Random Forest

\author{
Kurniabudi ${ }^{1}$, Abdul Harris ${ }^{2}$, Abdul Rahim ${ }^{3}$ \\ ${ }^{1}$ Sistem Komputer, STIKOM Dinamika Bangsa \\ ${ }^{2,3}$ Teknik Informatika, STIKOM Dinamika Bangsa \\ E-mail: ${ }^{1}$ kbudiz@yahoo.com, ${ }^{2}$ abdulharris@ @stikom-db.ac.id, ${ }^{3}$ abdulrahim@stikom-db.ac.id
}

\begin{abstract}
Abstrak
Tantangan deteksi serangan saat ini adalah jumlah trafik yang besar dan beragam serta hadir jenis serangan baru. Disisi lain, pesatnya pertumbuhan teknologi layanan komunikasi, menghasilkan trafik dengan informasi yang beragam. Sehingga diperlukan teknik baru untuk meningkatkan performa deteksi. DDoS merupakan salah satu serangan yang sering terjadi didunia maya. Serangan DDoS susah dibedakan dari trafik normal, selain itu, dalam deteksi serangan tidak semua fitur dianalisa. Terlalu banyak fitur yang tidak relevan akan menghasilkan kategori kelas yang tidak berhubungan dan membebani waktu komputasi. Oleh karena itu diperlukan seleksi fitur, selain itu seleksi fitur dapat meningkatkan akurasi. Penelitian ini bertujuan meningkatkan performa Random Forest dalam mendeteksi serangan DDoS dengan seleksi fitur menggunakan teknik Information Gain. Berdasarkan hasil eksperimen diperoleh bahwa teknik yang diusulkan mampu meningkatkan akurasi deteksi DDoS hingga 99.99\% dengan tingkat alarm palsu 0.001 .
\end{abstract}

Kata kunci: Seleksi fitur, DDoS, Information Gain, Random Forest, CICIDS-2017

\begin{abstract}
The challenge of attack detection now is the large and varied amount of traffic and new types of attacks. In other hand, the rapid growingly of communication services technology, has generated traffic with diverse information. So, the new techniques are needed to improve detection performance. DDoS is one of the most attacks in cyber. Its difficult to differentiate DDoS from norma traffic, in other hand, in attack detection not all feature used for analyzed. Too many irrelevant feature will contribute to unrelated class category and computation overhead. Therefore, feature selection is needed, because can improve accuracy. Feature selection is the one of the method has been used to improve classification algorithm accuracy. This study aims to improve the performance of Random Forest in detecting DDoS attacks by feature selection using Information Gain techniques. Based on the experimental results it was found that the proposed technique is able to increase the accuracy of DDoS detection up to $99.99 \%$ with a false alarm rate of 0.001 .
\end{abstract}

Keywords: feature selection, DDoS, Information Gain, Random Forest, CICIDS-2017

\section{PENDAHULUAN}

Meningkatnya ketergantungan masyarakat terhadap penggunaan sistem komputer pada berbagai aspek seperti keuangan, industri, kesehatan dan lain-lain menjadikan keamanan dunia maya menjadi penting, salah satunya yaitu deteksi intrusi atau serangan[1]. Tantangan deteksi serangan saat ini adalah jumlah trafik yang besar dan beragam serta hadir jenis serangan baru. 
Salah satu bentuk serangan yang popular adalah DDoS. Seperti dirilis dalam situs cisco.com, DDoS (Distributed Denial of Service) merupakan salah satu jenis serangan yang sering terjadi pada dunia maya di tahun 2018. Begitupula pada situs techrepublic.com disebutkan DDoS merupakan salah satu dari 6 (enam) jenis serangan di dunia maya yang paling popular di tahun 2018. Pada serangan $D D o S$, penyerang menciptakan jumlah permintaan yang sangat besar ke komputer korban dengan tujuan menolak permintaan normal atau menurunkan kualitas layanan[2]. Serangan $D D o S$ berdampak pada kerugian yang sangat besar, seperti berkurangnya pendapatan, kegagalan produksi, buruknya reputasi, pencurian dan lain-lain, hal inilah yang mendorong perlunya teknik pendeteksian dan pencegahan yang baik.[3].

Berbagai penelitian deteksi serangan DDoS telah berhasil mengembangkan berbagai teknik dan metode. Penelitian [4] mengusulkan deteksi serangan DDoS menggunakan teknik entropy, dengan membandingkan entropi alamat IP sumber dan entropi alamat IP tujuan dan berhasil mendeteksi DDoS secara efisien. Penelitian [5] yang mengusulkan model time series ARIMA dan chaotic system, model mampu mengklasifikasikan serangan hingga 99,5\%. Pada penelitian [6] ANN (Artificial Neural Network) diaplikasikan untuk mendeteksi DDoS dengan karakterisitik fitur khusus, solusi yang ditawarkan memiliki akurasi hingga 98\%. Sedangkan [7] merancang sistem deteksi DDoS pada lingkungan cloud computing dengan algorithma C.4.5. hasil eksperimen memperlihatkan hasil yang akurat dibandingan algorithma pembelajaran mesin yang lain.

Meskipun dari penelitian-penelitian sebelumnya telah dihasilkan berbagai metode dan teknik baru untuk mendeteksi serangan, salah satunya serangan DDoS. Namun, seiring meningkatnya perkembangan sistem keamanan jaringan maya, muncul berbagai bentuk baru serangan yang dimodifikasi dari serangan yang ada. Disisi lain dengan berkembangnya berbagai jenis layanan teknologi komunikasi, menghasilkan trafik jaringan yang sangat beragam dan berukuran besar, hal ini menjadi tantangan dalam deteksi serangan dikarenakan semakin banyak informasi (fitur) yang akan diolah. Pada dasarnya tidak semua fitur yang terdapat pada trafik memiliki pengaruh terhadap algorithma deteksi. Namun, diperlukan pengetahuan untuk menentukan fitur yang tepat dan relevan untuk mendeteksi serangan seperti DDoS. Dikarenakan sangat sulit membedakan DDoS dari trafik normal[8]. Selain itu, terlalu banyak fitur yang tidak relevan akan menghasilkan kategori kelas yang tidak berhubungan[9]. Mengacu pada penelitian [10]\&[11]disebutkan bahwa seleksi fitur dapat meningkatkan akurasi algorithma klasifikasi. Oleh karenanya penelitian ini bertujuan meningkatkan performa deteksi serangan DDoS dengan menggunakan teknik seleksi fitur. Pada penelitian ini Random Forest digunakan sebagai metoda klasifikasi yang akan ditingkatkan performanya, sedangkan teknik seleksi fitur menggunakan Information Gain. Penelitian ini juga menguji teknik seleksi fitur Information Gain dalam menghasilkan fitur yang relevan untuk mendeteksi serangan DDoS dan melakukan komparasi fitur hasil seleksi terhadap performa algorithma klasifikasi Naive Bayes, Bayes Network, OneR, Adaboost, RandomTree dan Random Forest dalam mendeteksi serangan DDoS.

\section{METODE PENELITIAN}

Pada bagian ini peneliti memaparkan kerangka penelitian, metoda dan dataset yang digunakan pada eksperimen penelitian.

\subsection{Kerangka Penelitian}

Pada penelitian ini penulis menggunakan beberapa tahapan kegiatan, yang disusun dalam kerangka penelitian pada gambar 1. Berdasarkan gambar 1, dapat dijelaskan tahapantahapan yang dilakukan dalam penelitian ini adalah sebagai berikut :

1. Persiapan data, pada tahapan ini penulis melakukan persiapan data diantaranya, mengubah format data dari csv ke arff. Menghilangkan fitur/atribut yang redundan. Kemudian melakukan pemisahan data sebagai sampel. Dimana pada penelitian ini sebagai sampel digunakan $20 \%$ dari dataset.

2. Seleksi fitur, teknik seleksi fitur yang digunakan pada penelitian ini adalah 
Information Gain yang merupakan teknik filtered-based. Tujuan dari seleksi fitur ini adalah untuk mendapatkan fitur yang paling relevan untuk digunakan dalam deteksi serangan DDoS.

3. Training, dataset hasil seleksi fitur, di training dengan menggunakan beberapa metode klasifikasi. Tujuannya adalah untuk melihat perbanding performa metode klasifikasi dalam mendeteksi serangan DDoS. Metode yang digunakan dalam training adalah : Nä̈ve Bayes, Bayes Network, OneR, AdaBoost, Random Tree dan Random Forest. Untuk proses training peneliti menggunakan 3 (tiga) mode pengujian yaitu : use training set, 5-fold cross validation dan 10-fold cross validation.

4. Analisis dan Interpretasi, berdasarkan hasil eksperimen kemudian data dianalisis dan diinterprestasi. Dalam penelitian ini, performa metode klasifikasi diukur dengan tingkat Acuracy, TPR, FPR, Precision, Recall, Time to Building Model dan Process Time

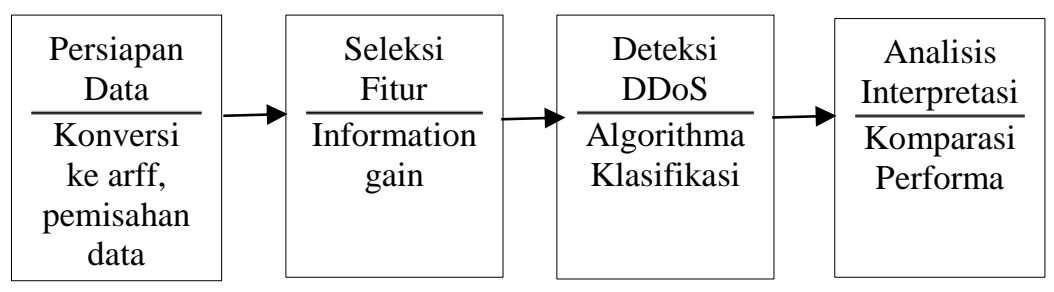

Gambar 1 Tahapan Penelitian

\subsection{Information Gain}

Teknik seleksi fitur secara luas telah digunakan hampir dibanyak bidang seperti kategorisasi teks, analisi genomic, deteksi intrusi, bioinformatic dan lain-lain. Salah satu teknik seleksi fitur adalah information gain. Information Gain menggunakan pendekatan penyaringan (filtered-based)[7]. Information Gain (IG) menghitung entropi setiap fitur. Makin tinggi entropi, makin banyak informasi yang dimiliki fitur tersebut. Fitur ini akan dipilih untuk digunakan pada algorithma klasifikasi, untuk membedakan data yang tidak dikenal menjadi kelas serangan[8]. Berdasarkan [3] untuk menghitung information gain dilakukan dengan langkah:

- Panggil dataset

- Hitung entropy dataset dengan persamaan 1

$$
I(\text { parent })=-\sum_{i=1}^{k} P\left(h_{i}\right) \cdot \log _{2} P\left(h_{i}\right)
$$

Dimana $P\left(h_{i}\right)$ merupakan probabilitas dari $h_{i}$

- Pisahkan set menjadi subset menggunakan atribut/ fitur yang memiliki entropi minimum.

- Buat simpul decision tree dari atribut tersebut

- Hitung entropi dari simpul child, I( child $\left._{1}\right), I\left(\right.$ child $\left._{2}\right)$ menggunakan persamaan (1).

- Hitung entropi atribut/fitur dengan persamaan (2).

$$
I\left(\text { attribute }_{i}\right)=\sum_{v \in \text { Values }(A)} \frac{\mid \text { child }_{v} \mid}{\mid \text { attribute }_{i \mid}} I\left(\text { child }_{v}\right)
$$

- Hitung information gain menggunakan persamaan (3)

$$
G\left(\text { attribute }_{i}\right)=I(\text { parent })-I\left(\text { attribute }_{i}\right)
$$

- Proses berulang untuk semua atribut 


\subsection{Random Forest}

Random Forest termasuk algorithma klasifikasi berbasis bagging essemble yang popular. Random Forest terdiri atas banyak pohon keputusan (decission tree). Luaran dari random forest merupakan hasil voting dari masing-masing pohon (tree)[14]. Seandainya setiap classifier dalam ensemble merupakan decision tree classifier, maka kumpulan classifier adalah sebuah "forest" [15]. Dalam [16], random forest didefenisikan dengan sebuah forest terdiri atas $K$ tree $\left\{T_{1}, \ldots, T_{K}\right\}$, sebuah vektor random $\theta_{\mathrm{k}}$ dibentuk untuk tree $k_{t h}, k=1, \ldots, K$. Dimana $\theta_{\mathrm{k}}$ merupakan vektor random untuk pemodelan tree. Vektor ini didefenisikan sebagai konstruksi tree. Misalnya, dalam pemilihan acak, vektor-vektor ini terdiri dari bilangan bulat acak yang dipilih secara acak dari $\{1, \ldots, N\}$ dimana $N$ adalah jumlah pemisahan. Random Forest memiliki kelebihan yaitu menghasilkan error yang rendah, menghasilkan klasifikasi yang baik, dan dapat mengatasi data training yang sangat besar serta efektif untuk mengestimasi missing data[14].

Beberapa penelitian tentang deteksi serangan atau intrusi yang menggunakan metoda Random Forest, [17] yang membangun model hybrid untuk sistem deteksi intrusi dengan menggabungkan Rough Set Theory (RST) dan Random Forest. Model yang diusul menunjukkan kinerja yang lebih baik dibandingkan penelitian-penelitian sebelumnya. Sedangkan, dalam penelitiannya menggabungkan Gain Ration $(G R)$ sebagai teknik seleksi fitur dan Random Forest sebagai classifier. Dengan menggunakan NSL-KDD dataset hasil pengujian dengan 30 atribut menghasilkan Detection Rate (DR) sebesar $99.73 \%$ dan dengan 25 atribut menghasilkan DR sebesar 99.745\%[18]. Dalam beberapa penelitian deteksi serangan algorithma Random Forest menunjukkan kinerja yang baik, namun masih perlu ditingkatkan. Selain itu, algorithma ini belum diuji untuk data yang berdimensi besar, dengan jumlah fitur yang lebih banyak.

\subsection{Pengukuran Performa}

Untuk pengukuran performa pada penelitian ini penulis menggunakan confusion matrix seperti disajikan pada tabel 1 .

Tabel 1 Binary Confusion Matrix

\begin{tabular}{|c|c|c|c|}
\hline & & \multicolumn{2}{|c|}{ Prediksi } \\
\hline & & Normal & Serangan \\
\hline \multirow[t]{2}{*}{ Aktual } & Normal & TP & FP \\
\hline & Serangan & FN & $\mathrm{TN}$ \\
\hline
\end{tabular}

Dalam konteks IDS tabel 1 dapat dijelaskan sebagai berikut :

- FP (False Positive) : didefenisikan sebagai jumlah aktual normal yang terdeteksi sebagai serangan

- FN (False Negative) : didefenisikans sebagai kesalahan prediksi, dimana aktual serangan dideteksi sebagai normal

- TP (True Positive) : didefenisikan sebagai ketepatan prediksi, aktual normal terdeteksi sebagai normal

- TN (True Negative) : didefenisikan sebagai aktual serangan terdeteksi sebagai serangan.

Selanjutnya berdasarkan confusion matrix, peforma algorithma klasifikasi diukur berdasarkan:

a. Accuracy: didefinisikan sebagai tingkat kedekatan antara nilai pengkategorian dengan nilai aktual

$$
\text { Accuracy }=\frac{\mathrm{TP}+\mathrm{TN}}{\mathrm{TP}+\mathrm{TN}+\mathrm{FP}+\mathrm{FN}}
$$

b. True Positive Rate : yang didefenisikan sebagai aktual positif dikategorikan sebagai kelas positif.

$$
\text { True Positive Rate }=\frac{T P}{F N+T P}
$$


c. False Positive Rate: yang didefenisikan sebagai aktual negatif dikategorikan sebagai kelas positif

$$
\text { False Positive Rate }=\frac{\mathrm{FP}}{\mathrm{FP}+\mathrm{TN}}
$$

d. Recall : yang didefinisikan sebagai aktual positif dikategorikan dengan benar sebagai kelas positif.

$$
\text { Recall }=\frac{\mathrm{TP}}{\mathrm{TP}+\mathrm{FN}}
$$

e. Precission : didefenisikan sebagai ukuran estimasi probabilitas prediksi positif yang benar

$$
\text { Precission }=\frac{\mathrm{TP}}{\mathrm{TP}+\mathrm{FP}}
$$

Sedangkan untuk pengukuran Time Building Model dihitung, saat system membangun model training oleh aplikasi weka. Untuk Proses Time dihitung saat proses training dimulai hingga selesai.

\subsection{Dataset}

Penelitian ini menggunakan dataset CICIDS-2017 dari ISCX. Pada dataset CICIDS2017 terdapat trafik Normal dan Serangan. Pemilihan dataset ini, dikarenakan dataset ini mewakili beberapa hal diantaranya : kompleksitas, heterogenitas, interaksi lengkap dan lainlain[19]. Untuk trafik serangan terdiri beberapa jenis serangan secara umum yaitu : Bot, BruteForce, DoS/DDoS, Infiltration, PortScan dan Web-Attack. Dalam penelitian ini penulis hanya menggunakan $20 \%$ data dari dataset. Pada penelitian ini dataset yang digunakan telah dilakukan seleksi, yaitu hanya berisi trafik Normal dan serangan Dos/DDoS, detail data disajikan pada tabel 2. Menurut [20], pada dataset CICIDS-2017, untuk trafik serangan DDoS terdiri atas beberapa jenis yaitu : DDoS, DoS GoldenEye, DoS Hulk, DoS Slow-httptest, DoS Slowloris dan Hearthbleed. Setelah melalui proses persiapan data, terdapat 78 fitur pada dataset yang akan

\begin{tabular}{|c|c|}
\hline Jenis Data & Jumlah \\
\hline Normal & 454306 \\
\hline Dos/DDoS & 76445 \\
\hline Total & 530751 \\
\hline
\end{tabular}
digunakan pada eksperimen.

Tabel 2 Profil Data Penelitian

\subsection{Lingkungan Eksperimen}

Pada penelitian ini, untuk mendukung eksperimen seleksi fitur dan deteksi DDoS dengan algorithma klasifika digunakan Notebook dengan Processor Core i7-7500U 2,7 GHz(4 $C P U$ ) dan 8 GB RAM. Sistem operasi yang digunakan Windows 10 Pro 64-bit. Alat bantu analis menggunakan weka 3.9. Weka merupakan perangkat lunak datamining dan machine learning. Open-source yang pertama kali diimplementasikan di University of Waikato, New Zealand pada tahun 1997 [21]. Weka memiliki sejumlah besar skema pembelajaran untuk klasifikasi, klasterisasi dan prediksi regresi numerik[22].

\section{HASIL DAN PEMBAHASAN}

Pada bagian ini peneliti memaparkan hasil eksperimen seleksi fitur dan hasil training beberapa algorithma klasifikasi untuk mendeteksi serangan DDoS. Pada bagian ini juga disampaikan analisis terhadap komparasi performa klasifikasi. 


\subsection{Hasil Seleksi Fitur}

Seperti dijelaskan diawal, dalam eksperimen ini penulis menggunakan teknik Information Gain sebagai teknik seleksi fitur. Melalui teknik ini diharapkan akan didapatkan fitur yang relevan untuk digunakan dalam mendeteksi serangan DDoS. Eksperimen seleksi fitur dilakukan menggunakan alat bantu Weka. Proses seleksi fitur menggunakan weka sebagai berikut:

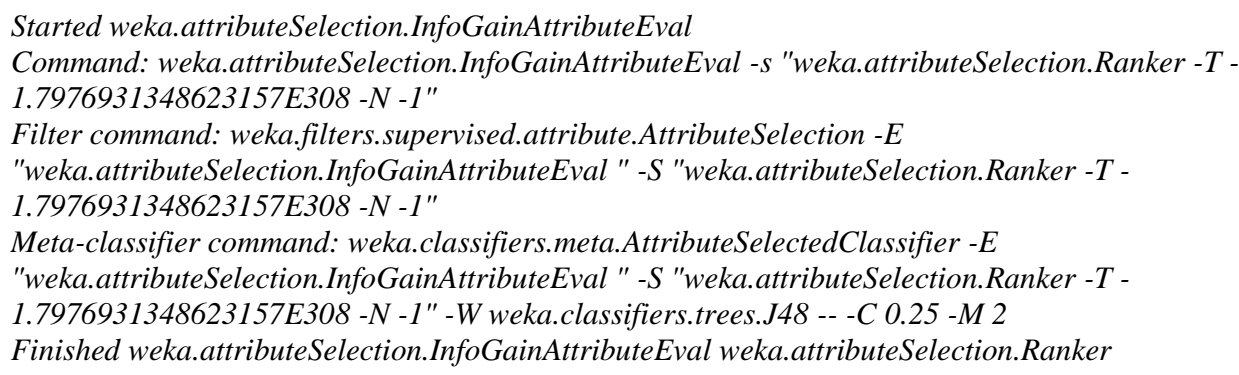

Started weka.attributeSelection.InfoGainAttributeEval

Command: weka.attributeSelection.InfoGainAttributeEval -s "weka.attributeSelection.Ranker -T -

1.7976931348623157E308 -N -1"

Filter command: weka.filters.supervised.attribute.AttributeSelection -E

"weka.attributeSelection.InfoGainAttributeEval " -S "weka.attributeSelection.Ranker -T -

$1.7976931348623157 E 308-N-1$ "

Meta-classifier command: weka.classifiers.meta.AttributeSelectedClassifier -E

"weka.attributeSelection.InfoGainAttributeEval " -S "weka.attributeSelection.Ranker -T -

$1.7976931348623157 E 308-N-1$ " -W weka.classifiers.trees.J48 -- -C 0.25 -M 2

Finished weka.attributeSelection.InfoGainAttributeEval weka.attributeSelection.Ranker

Selanjutnya dari proses seleksi fitur menggunakan Information Gain di dapatkan hasil seperti disajikan pada tabel 3. Information Gain menghasilkan perangkingan fitur berdasarkan nilai bobot. Dalam penelitian ini penulis menetapkan fitur dengan bobot $>0.3$ yang akan digunakan sebagai fitur terpilih serperti disajikan pada tabel 4. Berdasarkan hasil eksperimen, dari 78 fitur, dengan menggunakan teknik Information Gain dan penetapan bobot minimal maka didapatkan 19 fitur terpilih. Selanjutnya fitur-fitur ini digunakan untuk mendeteksi serangan DDoS.

Tabel 3 Rangking Fitur berdasarkan Information Gain

\begin{tabular}{|c|c|c|c|c|c|c|c|}
\hline Rank.\# & Bobot & ID & Nama Fitur & Rank.\# & Bobot & ID & Nama Fitur \\
\hline 1 & 0.4034879 & 65 & Subflow Bwd Bytes & 40 & 0.1898138 & 74 & Idle Mean \\
\hline 2 & 0.4034879 & 13 & Total Length of Bwd Packets & 41 & 0.1880105 & 77 & Idle Min \\
\hline 3 & 0.3742486 & 54 & Avg Bwd Segment Size & 42 & 0.1738925 & 62 & Subflow Fwd Packets \\
\hline 4 & 0.3742486 & 20 & Bwd Packet Length Mean & 43 & 0.1738925 & 10 & Total Fwd Packets \\
\hline 5 & 0.3717176 & 18 & Bwd Packet Length Max & 44 & 0.1607988 & 31 & Bwd IAT Min \\
\hline 6 & 0.3708806 & 66 & Init_Win_bytes_forward & 45 & 0.1498899 & 6 & Bwd IAT Std \\
\hline 7 & 0.3708107 & 8 & Destination Port & 46 & 0.145804 & 2 & Flow Bytes/s \\
\hline 8 & 0.3517825 & 52 & Average Packet Size & 47 & 0.1428483 & 19 & Bwd Packet Length Min \\
\hline 9 & 0.3499329 & 39 & Max Packet Length & 48 & 0.1341145 & 3 & Flow Packets/s \\
\hline 10 & 0.3381345 & 41 & Packet Length Std & 49 & 0.1275302 & 37 & Fwd Packets/s \\
\hline 11 & 0.3356896 & 63 & Subflow Fwd Bytes & 50 & 0.1266325 & 15 & Fwd Packet Length Min \\
\hline 12 & 0.3356896 & 12 & Total Length of Fwd Packets & 51 & 0.1262031 & 38 & Min Packet Length \\
\hline 13 & 0.3314553 & 14 & Fwd Packet Length Max & 52 & 0.1116554 & 27 & Fwd IAT Min \\
\hline 14 & 0.3289957 & 1 & Bwd Packet Length Std & 53 & 0.1099881 & 7 & Bwd Packets/s \\
\hline 15 & 0.3221081 & 67 & Init_Win_bytes_backward & 54 & 0.0868865 & 23 & Flow IAT Min \\
\hline 16 & 0.3220426 & 26 & Fwd IAT Max & 55 & 0.084843 & 68 & act_data_pkt_fwd \\
\hline 17 & 0.3142141 & 40 & Packet Length Mean & 56 & 0.0508056 & 51 & Down/Up Ratio \\
\hline 18 & 0.3021613 & 24 & Fwd IAT Total & 57 & 0.0404799 & 47 & ACK Flag Count \\
\hline 19 & 0.3004814 & 22 & Flow IAT Max & 58 & 0.0311414 & 43 & FIN Flag Count \\
\hline 20 & 0.2958327 & 42 & Packet Length Variance & 59 & 0.0299443 & 75 & Idle Std \\
\hline 21 & 0.2855234 & 36 & Bwd Header Length & 60 & 0.0205767 & 48 & URG Flag Count \\
\hline
\end{tabular}




\begin{tabular}{|r|l|r|l|r|r|r|l|}
\hline 22 & 0.2736278 & 9 & Flow Duration & 61 & 0.018671 & 71 & Active Std \\
\hline 23 & 0.2735282 & 25 & Fwd IAT Mean & 62 & 0.0075712 & 69 & min_seg_size_forward \\
\hline 24 & 0.2486764 & 17 & Fwd Packet Length Std & 63 & 0.0063766 & 32 & Fwd PSH Flags \\
\hline 25 & 0.243348 & 64 & Subflow Bwd Packets & 64 & 0.0063766 & 44 & SYN Flag Count \\
\hline 26 & 0.243348 & 11 & Total Backward Packets & 65 & 0.0003598 & 46 & PSH Flag Count \\
\hline 27 & 0.2361221 & 55 & Fwd Header Length & 66 & 0.0000567 & 50 & ECE Flag Count \\
\hline 28 & 0.2346869 & 5 & Fwd IAT Std & 67 & 0.0000567 & 45 & RST Flag Count \\
\hline 29 & 0.2327158 & 30 & Bwd IAT Max & 68 & 0.0000224 & 34 & Fwd URG Flags \\
\hline 30 & 0.225487 & 70 & Active Mean & 69 & 0.0000224 & 49 & CWE Flag Count \\
\hline 31 & 0.2249796 & 21 & Flow IAT Mean & 70 & & 35 & Bwd URG Flags \\
\hline 32 & 0.223046 & 73 & Active Min & 71 & & 56 & Fwd Avg Bytes/Bulk \\
\hline 33 & 0.2206013 & 72 & Active Max & 72 & & 59 & Bwd Avg Bytes/Bulk \\
\hline 34 & 0.2149794 & 28 & Bwd IAT Total & 73 & & 33 & Bwd PSH Flags \\
\hline 35 & 0.2149494 & 16 & Fwd Packet Length Mean & 74 & & 61 & Bwd Avg Bulk Rate \\
\hline 36 & 0.2149494 & 53 & Avg Fwd Segment Size & 75 & & 60 & Bwd Avg Packets/Bulk \\
\hline 37 & 0.2014082 & 29 & Bwd IAT Mean & 76 & 0 & 57 & Fwd Avg Packets/Bulk \\
\hline 38 & 0.1984862 & 4 & Flow IAT Std & 77 & 0 & 58 & Fwd Avg Bulk Rate \\
\hline 39 & 0.197735 & 76 & Idle Max & & & & \\
\hline
\end{tabular}

Tabel 4 Fitur-fitur hasil Seleksi

\begin{tabular}{|r|r|r|l|r|r|l|l|}
\hline Rank.\# & \multicolumn{1}{|c|}{ Bobot } & ID & \multicolumn{1}{|c|}{ Nama Fitur } & Rank.\# & Bobot & ID & \multicolumn{1}{|c|}{ Nama Fitur } \\
\hline 1 & 0,403488 & 65 & Subflow Bwd Bytes & 11 & 0,335690 & 63 & Subflow Fwd Bytes \\
\hline 2 & 0,403488 & 13 & Total Length of Bwd Packets & 12 & 0,335690 & 12 & Total Length of Fwd Packets \\
\hline 3 & 0,374249 & 54 & Avg Bwd Segment Size & 13 & 0,331455 & 14 & Fwd Packet Length Max \\
\hline 4 & 0,374249 & 20 & Bwd Packet Length Mean & 14 & 0,328996 & 1 & Bwd Packet Length Std \\
\hline 5 & 0,371718 & 18 & Bwd Packet Length Max & 15 & 0,322108 & 67 & Init_Win_bytes_backward \\
\hline 6 & 0,370881 & 66 & Init_Win_bytes_forward & 16 & 0,322043 & 26 & Fwd IAT Max \\
\hline 7 & 0,370811 & 8 & Destination Port & 17 & 0,314214 & 40 & Packet Length Mean \\
\hline 8 & 0,351783 & 52 & Average Packet Size & 18 & 0,302161 & 24 & Fwd IAT Total \\
\hline 9 & 0,349933 & 39 & Max Packet Length & 19 & 0,300481 & 22 & Flow IAT Max \\
\hline 10 & 0,338135 & 41 & Packet Length Std & & & & \\
\hline
\end{tabular}

\subsection{Performa Klasifikasi}

Untuk menguji performa klasifikasi dilakukan eksperimen deteksi DDoS menggunakan fitur hasil seleksi yang telah dibahas pada bagian sebelumnya. Untuk performa deteksi pada penelitian menggunakan Accuracy, True Positive Rate, False Positive Rate, Recall dan Precission secara konsep menggunakan persamaan (4)-(8). Pada eksperimen ini untuk menguji pengaruh fitur hasil seleksi terhadap algorithma klasifikasi Random Tree dan dikomparasi dengan Nä̈ve bayes, Bayes Network, OneR, Adaboost dan Random Tree penulis menggunakan weka. Detail proses training algorithma klasifikasi menggunakan weka disajikan sebagai berikut :

a. Proses training naive bayes

Started weka.classifiers.bayes.NaiveBayes

Command: weka.classifiers.bayes.NaiveBayes

Finished weka.classifiers.bayes.NaiveBayes 
b. Proses training Bayes nework

Started weka.classifiers.bayes.BayesNet

Command: weka.classifiers.bayes.BayesNet $-D-Q$

weka.classifiers.bayes.net.search.local.K2 -- -P 1 -S BAYES -E

weka.classifiers.bayes.net.estimate.SimpleEstimator -- -A

Finished weka.classifiers.bayes.BayesNet

c. Proses training OneR

Started weka.classifiers.rules.OneR

Command: weka.classifiers.rules.OneR -B 6

Finished weka.classifiers.rules.OneR

d. Proses training Adaboost

Started weka.classifiers.meta.AdaBoostM1

Command: weka.classifiers.meta.AdaBoostM1 -P 100 -S 1 -I 10 -W

weka.classifiers.trees.DecisionStump

Finished weka.classifiers.meta.AdaBoostM1

e. Proses training Random Tree

Started weka.classifiers.trees.RandomTree

Command: weka.classifiers.trees.RandomTree -K $0-M 1.0-V 0.001-S 1$

Finished weka.classifiers.trees.RandomTree

f. Proses training Random Forest

Started weka.classifiers.trees.RandomForest

Command: weka.classifiers.trees.RandomForest -P 100 -I 100 -num-slots 1 -K 0 -M 1.0 -

V0.001 -S 1

Finished weka.classifiers.trees.RandomForest

Dalam eksperimen digunakan 3 (tiga) jenis pengujian yaitu, 1)use training set, 205 Fold Cross Validation dan 3) 10-Fold Cross Validation. Berdasarkan hasil ekperimen, dari sisi akurasi secara umum Random Forest memiliki tingkat akurasi yang lebih tinggi dibandingkan Nä̈ve bayes, Bayes Network, OneR, Adaboost dan Random Tree. Dari 3 (tiga) proses pengujian yang digunakan pada eksperimen, hasil yang di sajikan pada tabel 5 memperlihatkan Random Forest memiliki akurasi yang lebih tinggi.

Tabel 5 Akurasi

\begin{tabular}{|l|r|r|r|r|r|r|}
\hline \multicolumn{1}{|c|}{ Mode Pengujian } & \multicolumn{1}{c|}{ Naïve Bayes } & \multicolumn{1}{c|}{ Bayes Net } & \multicolumn{1}{c|}{ OneR } & AdaBoost & \multicolumn{1}{c|}{ Random Tree } & Random Forest \\
\hline Use training Set & 94.14 & 99.61 & 94.89 & 96.89 & 99.99 & 99.99 \\
\hline 5-Fold Cross Validation & 94.44 & 99.59 & 94.89 & 96.89 & 99.92 & 99.95 \\
\hline 10-Fold Cross Validation & 94.35 & 99.59 & 94.89 & 96.89 & 99.92 & 99.95 \\
\hline
\end{tabular}

Pada tabel 6 disajikan komparasi True Positive Rate untuk masing-masing algorithma klasifikasi dengan 3 (tiga) proses pengujian. Hasil memperlihatkan Random Tree dan Random Forest memiliki nilai TPR yang sama jika dibandingkan Nä̈ve bayes, Bayes network, OneR dan Adaboost. Meskipun pada proses training dengan use training set dan 5-fold cross validation memperoleh nilai yang sama dengan Random Tree.

Tabel 6 True Positive Rate

\begin{tabular}{|l|r|r|r|r|r|r|}
\hline \multicolumn{1}{|c|}{ Mode Pengujian } & \multicolumn{1}{c|}{ Naïve Bayes } & \multicolumn{1}{c|}{ Bayes Net } & \multicolumn{1}{c|}{ OneR } & \multicolumn{1}{c|}{ AdaBoost } & Random Tree & Random Forest \\
\hline Use training Set & 0.996 & 0.941 & 0.949 & 0.969 & 1.000 & 1.000 \\
\hline 5-Fold Cross Validation & 0.996 & 0.944 & 0.949 & 0.969 & 0.999 & 0.999 \\
\hline 10-Fold Cross Validation & 0.996 & 0.943 & 0.949 & 0.969 & 0.999 & 1.000 \\
\hline
\end{tabular}


Sedangkan untuk nilai False Positive Rate yang disajikan pada tabel 7, memperlihatkan Random Forest memiliki nilai FPR lebih rendah dibandingkan Nä̈ve bayes, Bayes network, OneR, Adaboost dan Random Tree.

Tabel 7 False Positive Rate

\begin{tabular}{|l|r|r|r|r|r|r|}
\hline Mode Pengujian & \multicolumn{1}{|c|}{ Naïve Bayes } & \multicolumn{1}{c|}{ Bayes Net } & \multicolumn{1}{c|}{ OneR } & \multicolumn{1}{c|}{ AdaBoost } & Random Tree & Random Forest \\
\hline Use training Set & 0.006 & 0.012 & 0.303 & 0.045 & 0.000 & 0.000 \\
\hline 5-Fold Cross Validation & 0.006 & 0.012 & 0.303 & 0.045 & 0.002 & 0.001 \\
\hline 10-Fold Cross Validation & 0.006 & 0.012 & 0.303 & 0.045 & 0.002 & 0.001 \\
\hline
\end{tabular}

Untuk nilai precision yang disajikan pada tabel 8, memperlihatkan pada pengujian menggunakan user training set dan 5-fold cross validation, Random Forest dan Random Tree memiliki nilai precission yang sama dan lebih tinggi dibandingkan Nä̈ve bayes, Bayes network, OneR dan AdaBoost. Sedangkan untuk pengujian menggunakan 10-fold cross validation, Random Forest memiliki nilai precision yang paling tinggi dibandingkan Nä̈ve bayes, Bayes network, OneR, AdaBoost dan Random Tree.

Tabel 8 Precision

\begin{tabular}{|l|r|r|r|r|r|r|}
\hline \multicolumn{1}{|c|}{ Mode Pengujian } & \multicolumn{1}{c|}{ Naïve Bayes } & \multicolumn{1}{c|}{ Bayes Net } & \multicolumn{1}{c|}{ OneR } & \multicolumn{1}{c|}{ AdaBoost } & Random Tree & Random Forest \\
\hline Use training Set & 0.958 & 0.996 & 0.952 & 0.971 & 1.000 & 1.000 \\
\hline 5-Fold Cross Validation & 0.960 & 0.996 & 0.952 & 0.971 & 0.999 & 0.999 \\
\hline 10-Fold Cross Validation & 0.959 & 0.996 & 0.952 & 0.971 & 0.999 & 1.000 \\
\hline
\end{tabular}

Untuk nilai recall pada tabel 9, memperlihatkan pada pengujian menggunakan user training set dan 5-fold cross validation, Random Forest dan Random Tree memiliki nilai recall yang sama dan lebih tinggi dibandingkan Nä̈ve bayes, Bayes network, OneR dan AdaBoost. Sedangkan untuk pengujian dengan 10-fold cross validation, Random Forest memiliki nilai recall yang tertinggi jika dibandingkan dibandingkan Naïve bayes, Bayes network, OneR, AdaBoost dan Random Tree.

Tabel 9 Recall

\begin{tabular}{|l|r|r|r|r|r|r|}
\hline \multicolumn{1}{|c|}{ Mode Pengujian } & \multicolumn{1}{c|}{ Naïve Bayes } & \multicolumn{1}{c|}{ Bayes Net } & \multicolumn{1}{c|}{ OneR } & \multicolumn{1}{c|}{ AdaBoost } & \multicolumn{1}{c|}{ Random Tree } & \multicolumn{1}{c|}{ Random Forest } \\
\hline Use training Set & 0.941 & 0.996 & 0.949 & 0.969 & 1.000 & 1.000 \\
\hline 5-Fold Cross Validation & 0.944 & 0.996 & 0.949 & 0.969 & 0.999 & 0.999 \\
\hline 10-Fold Cross Validation & 0.943 & 0.996 & 0.949 & 0.969 & 0.999 & 1.000 \\
\hline
\end{tabular}

Selanjutnya untuk waktu yang diperlukan membangun model disajikan pada tabel 10 . Data pada tabel 10 memperlihatkan bahwa jika dibandingkan dengan Naïve bayes, Bayes network, OneR, Adaboost dan Random Tree, Random Forest memiliki waktu yang lebih lama.

Tabel 10 Time Building Model(s)

\begin{tabular}{|l|r|r|r|r|r|r|}
\hline \multicolumn{1}{|c|}{ Mode Pengujian } & \multicolumn{1}{c|}{ Naïve Bayes } & \multicolumn{1}{c|}{ Bayes Net } & \multicolumn{1}{c|}{ OneR } & AdaBoost & Random Tree & Random Forest \\
\hline Use training Set & 1.84 & 21.56 & 2.38 & 38.79 & 2.96 & 295.09 \\
\hline 5-Fold Cross Validation & 1.68 & 20.63 & 3.30 & 39.15 & 2.74 & 291.79 \\
\hline 10-Fold Cross Validation & 1.61 & 20.64 & 3.33 & 46.20 & 2.73 & 290.28 \\
\hline
\end{tabular}

Begitupula halnya dengan waktu proses yang disajikan pada tabel 11. Data pada tabel 11 memperlihatkan Random Forest membutuhkan waktu proses yang lebih lama jika dibandingkan dengan Nä̈ve bayes, Bayes network, OneR, Adaboost dan Random Tree. 
Berdasarkan data pada tabel 10 dan 11, dapat disimpulkan, meskipun dari sisi akurasi, $T P R, F P R$, precision dan recall, Random Forest unggul dibandingkan algorithma lain, namun Random Forest memiliki waktu yang lebih lama untuk membangun model dan proses. Hal ini tentunya menjadi tantangan bagi peneliti untuk menghasilkan metode deteksi yang akurat namun memiliki waktu komputasi yang rendah.

Tabel 11 Process Time(s)

\begin{tabular}{|l|r|r|r|r|r|r|}
\hline Mode Pengujian & \multicolumn{1}{|c|}{ Naïve Bayes } & Bayes Net & OneR & AdaBoost & Random Tree & Random Forest \\
\hline Use training Set & 25 & 27 & 4 & 40 & 6 & 303 \\
\hline 5-Fold Cross Validation & 15 & 112 & 16 & 226 & 26 & 1454 \\
\hline 10-Fold Cross Validation & 38 & 255 & 29 & 585 & 70 & 5208 \\
\hline
\end{tabular}

\section{KESIMPULAN DAN SARAN}

Berdasarkan data hasil eksperimen maka dapat disimpulkan bahwa teknik seleksi fitur Information Gain mampu meningkatkan performa metoda klasifikasi khususnya Random Forest yang memiliki performa yang lebih baik dibandingkan Nä̈ve Bayes, Bayes Network, OneR, AdaBoost dan Random Tree dengan tangkat akurasi $99.99 \%$ pada pengujian seluruh data training dan $99.95 \%$ pada pengujian menggunakan 10 -fold cross validation. Namun disisi lain, Random Forest memiliki waktu yang lebih lama untuk membangun model dan proses training jika dibanding Nä̈ve Bayes, Bayes Network, OneR, AdaBoost dan Random Tree.

Pada eksperimen yang dilakukan pada penelitian ini, peneliti menggunakan Information Gain sebagai teknik seleksi fitur terhadap dataset CICIDS-2017 dalam mendeteksi serangan DDoS. Untuk penelitian selanjutnya dapat digunakan teknik seleksi fitur lain yang mungkin dapat meningkatkan performa deteksi serangan DDoS. Selain penggunaanteknik klasifikasi yang lain perlu dipertimbangkan dalam penelitian berikutnya, khususnya yang memiliki performa yang lebih baik dengan waktu komputasi yang rendah.

\section{DAFTAR PUSTAKA}

[1] R. Zuech, T. M. Khoshgoftaar, and R. Wald, "Intrusion detection and Big Heterogeneous Data : a Survey," 2015.

[2] J. David and C. Thomas, "DDoS attack detection using fast entropy approach on flowbased network traffic," Procedia Comput. Sci., vol. 50, pp. 30-36, 2015.

[3] N. A. Singh, J. Singh, and T. De, "Distributed denial of service attack detection using naive bayes classifier through info gain feature selection," ACM Int. Conf. Proceeding Ser., vol. 25-26-Augu, 2016.

[4] Y. Chen, "DDoS Detection Method Based on Chaos Analysis of Network Traffic Entropy," vol. 18, no. 1, pp. 114-117, 2014.

[5] S. M. T. Nezhad, M. Nazari, and E. A. Gharavol, "A Novel DoS and DDoS Attacks Detection Algorithm Using ARIMA Time Series Model and Chaotic System in Computer Networks," IEEE Commun. Lett., vol. 20, no. 4, pp. 700-703, 2016.

[6] A. Saied, R. E. Overill, and T. Radzik, "Detection of known and unknown DDoS attacks using Artificial Neural Networks," Neurocomputing, vol. 172, pp. 385-393, 2016.

[7] M. Zekri, S. El Kafhali, N. Aboutabit, and Y. Saadi, "DDoS attack detection using machine learning techniques in cloud computing environments," Proc. 2017 Int. Conf. Cloud Comput. Technol. Appl. CloudTech 2017, vol. 2018-Janua, pp. 1-7, 2018.

[8] Y. Chen, X. Ma, and X. Wu, "DDoS detection algorithm based on preprocessing network traffic predicted method and chaos theory," IEEE Commun. Lett., vol. 17, no. 5, pp. 1052-1054, 2013. 
[9] K. J. Singh and T. De, "Efficient Classification of DDoS Attacks Using an Ensemble Feature Selection Algorithm,” J. Intell. Syst., 2017.

[10] A. I. Madbouly, A. M. Gody, and T. M. Barakat, "Relevant Feature Selection Model Using Data Mining for Intrusion Detection System," Int. J. Eng. Trends Technol., vol. 9, no. 10, pp. 501-512, 2014.

[11] M. S. Pervez and D. M. Farid, "Feature selection and intrusion classification in NSLKDD cup 99 dataset employing SVMs," Ski. 2014 - 8th Int. Conf. Software, Knowledge, Inf. Manag. Appl., 2014.

[12] T. A. Alhaj, M. M. Siraj, A. Zainal, H. T. Elshoush, and F. Elhaj, "Feature selection using information gain for improved structural-based alert correlation," PLoS One, vol. 11, no. 11, pp. 1-18, 2016.

[13] Akashdeep, I. Manzoor, and N. Kumar, "A feature reduced intrusion detection system using ANN classifier," Expert Syst. Appl., vol. 88, pp. 249-257, 2017.

[14] D. Summeet and D. Xian, Data Mining and Machine Learning in Cybersecurity. CRC Press, 2011.

[15] J. Han, Data Mining: Concepts and Techniques (The Morgan Kaufmann Series in Data Management Systems). 2011.

[16] B. LEO, "Random Forests," Mach. Learn., vol. 45, no. 1, pp. 5-32, 2001.

[17] J. Jiang, Q. Wang, Z. Shi, B. Lv, and B. Qi, "RST-RF: A hybrid model based on rough set theory and random forest for network intrusion detection," ACM Int. Conf. Proceeding Ser., pp. 77-81, 2018.

[18] R. K. Singh, S. Dalal, V. K. Chauhan, and D. Kumar, "Optimization of FAR in Intrusion Detection System by Using Random Forest Algorithm," SSRN Electron. J., pp. 3-6, 2019.

[19] I. Sharafaldin, A. H. Lashkari, and A. A. Ghorbani, "Toward generating a new intrusion detection dataset and intrusion traffic characterization," ICISSP 2018 - Proc. 4th Int. Conf. Inf. Syst. Secur. Priv., vol. 2018-Janua, no. Cic, pp. 108-116, 2018.

[20] R. Panigrahi and S. Borah, "A detailed analysis of CICIDS2017 dataset for designing Intrusion Detection Systems," Int. J. Eng. Technol., vol. 7, no. 3.24 Special Issue 24, pp. 479-482, 2018.

[21] T. Garg and S. S. Khurana, "Comparison of classification techniques for intrusion detection dataset using WEKA," Int. Conf. Recent Adv. Innov. Eng. ICRAIE 2014, 2014.

[22] B. Cui and S. He, "Anomaly detection model based on hadoop platform and weka interface," Proc. - 2016 10th Int. Conf. Innov. Mob. Internet Serv. Ubiquitous Comput. IMIS 2016, pp. 84-89, 2016. 